\title{
Socio-Psychological Readiness to Create a Family Among Modern Youth
}

\author{
Elena Voropai ${ }^{1}$, Polina Udachina ${ }^{1}$, Natalya Lupenko ${ }^{1}$
}

\author{
${ }^{1}$ Kuban State University, Russia \\ *Email: jewo@mail.ru
}

\begin{abstract}
This article is devoted to the consideration of the problems of the social and psychological readiness of modern young men and women for family life. The relevance of the study of this problem is due to the fact that there has been a need to develop a purposeful, effective program for preparing young people for family life in modern Russian society, since marriage and family relations are leading in human relations. The formation of readiness for family life is an integral part of the general problem of modern education of the younger generation. The novelty of the research lies in obtaining new empirical data on the features of the content and structural characteristics of the future family image in modern youth. This article provides empirical data confirming the relevance of the described problem in solving an urgent scientific problem - ensuring the formation of readiness of young men and women for marriage and family relations.
\end{abstract}

Keywords: Family image, Preparation for future family life, Family roles, Ideas about the family, Readiness for marriage.

\section{INTRODUCTION}

\subsection{The current state of the problem of social and psychological readiness of youth to create a family}

These days, the problem of preparing adolescents and young people for future family life is becoming more and more acute. The transformation and strengthening of marriage and family relations on the scale of the entire Russian society and the creation of a strong family in each individual case requires certain knowledge, skills, abilities and competencies. An average modern Russian family is increasingly focusing on its inner life, and the role of marital relations in ensuring its stability is growing. Upbringing of the younger generation is an important tool through which different countries seek to resolve the above family problem. Since not every family can carry out the correct all-round premarital education of young people and school curricula currently do not provide for the study of the ethics and psychology of family life, there is a need for systematic and purposeful psychological and pedagogical work with modern youth, the main goal of which is to form readiness for marriage and family life.

\subsubsection{Family as a socio-psychological phenomenon and a necessary condition for the development of society}

A theoretical analysis of scientific literature has shown that on the basis of foreign and domestic modern research, authors discuss family problems [1,2] and carry out studies on changes in the stability and quality of marriage, depending on its duration $[3,4]$. Currently, most scientists agree that the quality of marriage is multidimensionally dependent on growing up [5], including the periods of childhood, adolescence and youth [6,7]). The authors consider the main positions of scientists regarding the processes of family transformation and its crisis phenomena $[8,9]$.

The changes in the modern world have led to the change in attitudes towards the role of family and marriage in human life. This is also associated with the transformations of the family itself as a social institution. The hierarchy of functions performed by the family and each of its members is changing. In these conditions, the 
study of the psychological readiness of young people for family life is becoming more and more relevant, since the conscious readiness for marriage is one of the conditions for family stability. Studies on the problem of psychological readiness for marriage allow us to conclude that, on the one hand, psychological readiness for marriage is an integrated psychological formation, including a stable positive motivation for entering into marriage, on the other hand, it is a process and result of a person's activity in the formation of family relationships. This is a generalized and schematized image of readiness for parenting, for motherhood or fatherhood [10].

\subsubsection{The level of readiness of modern students to create a family}

The level of readiness of young people to create a family is a certain quality of the personality of young people, who integrate the acceptance of family values as a social institution, special knowledge and skills in the field of family relations, housekeeping, interpersonal communication, family pedagogy and the length of the period of growing up caused by the difficulty for a young person finding oneself in the modern world [11]. The authors highlight the growing variability of the ways and rates of growing up: modern indicators, criteria, markers of adulthood are different on different paths of growing up, and, moreover, they are inconsistent and reversible. J. Arnett emphasizes the length of the growing up period and highlights the growing variability of the ways and rates of growing up: modern indicators, criteria, markers of adulthood are different on different paths of growing up, and, moreover, they are inconsistent and reversible [12]. Thus, readiness for marriage is seen as a system of attitudes towards marriage, the psychological components of which are the acceptance of a new system of responsibilities in relation to one's marriage partner and future children, and understanding of the rights and dignity of other members of the family union.

In order to study the ideas of a young family among young people, adolescence was not chosen by chance. Since it is high school students who are most sensitive to the ongoing changes in society, they are the most flexible in adapting to new requirements, they are the most educated and they are the resource on which the future of our country depends. The formation of the personality and significant psychological new formations appear and develop during this period of life. A person of this age period already has the ability to assess the reality and the people around him, as well as to forecast its further social activity and plan and assess his possibilities of selfrealization [13-15].

The purpose of the empirical research is to study the content and structural characteristics of the future family image in modern youth.

The goals are:
1. To study the problem of ideas about the family, family roles and future family life in Russian literature.

2. To carry out an empirical study of the ideas of family and family life among boys and girls, their relationship to marriage.

Object of research: the ideas of youth, reflecting the features of the image of their future family in changing social conditions.

Subject of research: differences in the ideas of boys and girls about the family, future spouse, family life.

The novelty of the research lies in obtaining new empirical data on the features of the content and structural characteristics of the future family image in modern youth.

Hypothesis: we can assume that the family ideas in adolescence differ in boys and girls.

\section{METHODS}

The study was undertaken on the basis of MBEI No. 1 named after seven Heroes of the Soviet Union, school graduates, the city of Slavyansk on-Kuban, and the following sample was taken: 80 students in grades 10-11, 40 boys and 40 girls, aged 16-17.

To study family attitudes, which makes possible establishing a hierarchy of family values and ideas about the distribution of roles in their implementation, as well as the role structure of a married couple, we used the questionnaire (REC) "Role expectations and claims in marriage", a methodology for diagnosing family relationships (A.N. Volkova). In the course of the study, we analyzed seven scales of family and revealed role expectations - the attitude of the husband and wife to actively fulfill the partner's family responsibilities, and role claims - the personal readiness of each partner to fulfill family roles. In this study authors provide the analysis of the results revealed in the course of the empirical study, the values of the Student's t-test of the level of significance $(p \leq 0.1)$ on general value scales on the expectations and claims of family values in unrelated samples of boys and girls.

In order to determine the characteristics of parentchild relationships, in the course of the study, the diagnosis of parental attitude was carried out using the parental attitude questionnaire (PAQ) (A.Ya. Varga V.V. Stolin). During the study, we analyzed five scales. B результате диагностики выявлялось проявление того или иного родительского отношения. To determine the presence of statistically significant differences in the types of parent-child relationships in unrelated samples in boys and girls, a statistical analysis of differences was carried out using the Student's t-test of the significance level $(p \leq 0.1)$. Data processing and analysis were carried out using the SPSS 7.5 statistical software package. We 
used descriptive statistics and the method of comparing average indicators by Student's t-test.

\section{RESULTS}

To study family attitudes, allowing to establish a hierarchy of family values and ideas about the distribution of roles and their implementation, as well as the role structure of a married couple, authors used the Questionnaire (REC) "Role expectations and claims in marriage" (A.N. Volkova). The results identified in the course of the empirical study are presented in table 1 .

Analyzing the results, the following tendencies predominate:

1. Scale "Sexual". Basically, we see that the significance of sexual relations in marriage is low. Estimates on this scale are: among boys (4.2), among girls (3.3), boys give more importance to sexual relations in the family than girls. This can be explained by the fact that for all the importance of this topic for adolescence, young people are shy and not inclined to be frank in this matter.

2. On the scale of "Personal identification" with a partner, all subjects have high scores: boys (7.7) and girls (7.6). Personal identification with a partner predominates (common values, needs, interests, ways of spending time). This can be explained by the age characteristics of early adolescence, in which there is still an element of youthful maximalism, the belief that the partner will think and feel the same way, share views and desires, needs and interests in everything.

3. "Household" scale. In terms of household expectations and claims, there are no significant differences. Attitude for the implementation of household functions of the family. Average indicators for boys - (6.1) in household expectations and (6.1) in household claims, for girls - (6.4) in household expectations and (5.6) in household claims. The girls expectations revealed their focus on that the partner had economic and household abilities. We can assume that girls have more expectations for a partner in this area than boys and are more focused on ensuring that the partner has economic abilities and takes the initiative in implementation of household functions of the family.

4. "Parental" scale reveals the attitude towards parental responsibilities. For boys the indicators have an average value (6.1) in expectations and (7.1) in claims, for girls - (6.9) in expectations and (4.7) in claims. We can assume that parental obligations remain a priority for girls, but there is an orientation that the partner will take on the main functions of raising and caring for children, and this attitude is more pronounced in girls than in boys. Young men are more focused on fulfilling the role of parents, presumably due to the experience in their parental family.

5. The "Social" scale. In this paragraph, we will consider the importance of social activity for boys and girls - an orientation toward professional, social, and business activity. On the "Social" scale, we revealed rather high indicators among boys - (6.5) in expectations and (7.7) in claims while girls got (6.8) in expectations and (8.1) in claims. For boys, the indicators are significantly higher in claims than for girls, which indicates the severity of their own professional needs. The personal readiness to show professional activity in expectations is expressed more than in claims among girls. We can assume that one of the main tasks of adolescence is the choice of a profession - young people strive to get an education and master a specialty [16]

6. The "emotional psychotherapeutic" scale also differs in rather high indices in role expectations among boys (7.3), and among girls (8.2). We can assume that the degree of orientation in girls that the partner will take on the role of the emotional leader of the family is much higher than in boys. In the role claims boys achieved (6.5), while girls resulted in (7.1). This shows that girls' desire to be a family "psychotherapist" is much higher

Table 1. Role expectations and ambitions in marriage

\begin{tabular}{|c|c|c|c|c|c|c|c|c|c|c|c|c|}
\hline & \multirow[t]{2}{*}{ Sexual } & \multirow[t]{2}{*}{$\begin{array}{l}\text { Personal } \\
\text { identifica } \\
\text { tion with } \\
\text { a spouse }\end{array}$} & \multicolumn{2}{|c|}{ Household } & \multicolumn{2}{|c|}{ Parental } & \multicolumn{2}{|c|}{ Social } & \multicolumn{2}{|c|}{$\begin{array}{c}\text { Emotional } \\
\text { psychotherapeut } \\
\text { ic }\end{array}$} & \multicolumn{2}{|c|}{ Attractiveness } \\
\hline & & & $\begin{array}{c}\text { expectati } \\
\text { ons }\end{array}$ & claims & $\begin{array}{l}\text { expect } \\
\text { ations } \\
\end{array}$ & claims & $\begin{array}{l}\text { expect } \\
\text { ations } \\
\end{array}$ & claims & $\begin{array}{l}\text { expect } \\
\text { ations }\end{array}$ & claims & $\begin{array}{l}\text { expect } \\
\text { ations } \\
\end{array}$ & claims \\
\hline $\mathrm{M}$ & 4.25 & 7.7 & 6.1 & 6.15 & 6.1 & 7.1 & 6.5 & 7.7 & 7.3 & 6.5 & 6.25 & 5.4 \\
\hline $\mathrm{F}$ & 3.35 & 7.6 & 6.4 & 5.6 & 6.9 & 4.7 & 6.8 & 8.1 & 8.2 & 7.1 & 7.1 & 6.7 \\
\hline $\mathrm{T}$ & 2.07 & 0.32 & 0.73 & 1.16 & 2.4 & 5 & 0.83 & 1.28 & 3.1 & 1.56 & 2.76 & 3 \\
\hline$p$ & 0.041 & 0.752 & 0.469 & 0.248 & 0.06 & 0,00003 & 0.409 & 0.201 & 0.002 & 0.122 & 0.007 & 0.003 \\
\hline
\end{tabular}

*T - Student's t-test; *p - level of pertinence 
due to the fact that factor of spiritual intimacy and emotional contact is important for them.

7. The "Attractiveness" scale represents the importance of the partner's appearance. Boys got average indicators: it is $(6.2)$ in role expectations and $(5,4)$ in claims, while for girls the indicators are higher: $(7,1)$ in expectations in $(6,7)$ claims. The results showed that the respondents demonstrate a typical young age attitude towards the importance of appearance and its compliance with the standards of modern fashion. Role expectations for girls more than for boys reflect the desire to have an attractive partner. Role claims among girls illustrate the attitude towards their own attractiveness, the desire to dress fashionably and beautifully. The role expectations among young men show the desire to have an outwardly attractive partner dominates, over their own attractiveness in claims.

According to the obtained data, we revealed statistically significant differences between the expectations and claims of boys and girls in the following parameters: on the "sexual" scale of family values, the reliability of differences is $(t=2.07$ at $\mathrm{p}=0.411)$; on the "parental" scale it is $(\mathrm{t}=2.4$ at $\mathrm{p}=0.016 ; \mathrm{t}=5$ at $\mathrm{p}=$ 0,00003), on the "emotional-psychotherapeutic" scale it is $(\mathrm{t}=3.1$ at $\mathrm{p}=0.002)$ in role expectations; on the scale of "attractiveness" it is $(\mathrm{t}=2.7$ at $\mathrm{p}=0.007 ; \mathrm{t}=3$ at $\mathrm{p}=$ $0.003)$

We did not find any statistically significant differences between boys and girls on the scale of family values: "personal identification with a spouse" is $(t=0.3$ at $\mathrm{p}=0.752)$ both in expectations and claims; "Household" is $(\mathrm{t}=0.7$ at $\mathrm{p}=0.469)(\mathrm{t}=1.1$ at $\mathrm{p}=2.48)$; "Social" is $(\mathrm{t}=0.8$ at $\mathrm{p}=0.409)(\mathrm{t}=1.2$ at $\mathrm{p}=0.201)$.

According to the obtained data, we can assume that the ideas about the family in adolescence differ among boys and girls. The results of the study showed that young men give more importance to sexual relations in the family than girls. Personal identification with a partner is recognized by girls to a greater extent than by boys. We also revealed that girls expect their partner to have economic abilities. The girls expressed an orientation towards the fact that the main functions of raising and caring for children will be taken over by a partner, while boys are more focused on fulfilling the role of a parent. The boys have expressed an orientation toward encouraging professional activity. The girls show the attitude towards their own attractiveness.

The study of the characteristics of parent-child relationships in boys and girls was carried out using the parental attitude questionnaire (PAQ). According to the obtained data, diagnostics of the types of parent-child relationships showed the following:

The high rates on the Acceptance - Rejection scale indicate that boys and girls have a clearly expressed positive attitude towards their future child. This type was identified in $90 \%$ of boys and $100 \%$ of girls.

Indicators on the "Cooperation" scale are quite high in $70 \%$ of girls, and in average level of $47.5 \%$ of boys. High scores for girls are a sign of genuine interest in child activities. It is typical for young men to assess the abilities and skills of their future child well, as well as to encourage it on independence and initiative.

$62.5 \%$ of boys and $47.5 \%$ of girls showed an average level of the "Symbiosis" relationship type. According to the results of diagnostics, we can assume that boys are more aimed at not establishing a sufficiently large distance between themselves and the child in the process of relationships.

The scale "Authoritarian hypersocialization", with indicators of $72.5 \%$ for girls and $67.5 \%$ for boys, characterizes an authoritarian attitude towards the child. This indicator is more demonstrative in boys than in girls.

$90 \%$ of boys and $95 \%$ of girls had a high level of the "little loser" type according to the criterion of "faith in the child", which is characterized by the attitude of parents towards their children, who perceive the child's failures as accidental and temporary.

As a result of diagnostics of boys and girls, we revealed that the predominant type of parent-child relationship was "acceptance". This type was identified in $80 \%$ of boys and $100 \%$ of girls. In the second position, $90 \%$ of boys and $95 \%$ of girls showed a high level of the "little loser" type of relationship. The third position is the type of relationship "symbiosis" with the indicators in

Table 2. Diagnostics of the types of parent-child relationships

\begin{tabular}{|l|c|c|}
\hline \multicolumn{1}{|c|}{ PAQ scale name } & $T$ & $p$ - level of significance \\
\hline Acceptance-Rejection & $5.088^{*}$ & 0,000002 \\
\hline Cooperation & $2.298^{*}$ & 0.024 \\
\hline Symbiosis & $2.211^{\star}$ & 0.029 \\
\hline Authoritarian hypersocialization & 0.716 & 0.475 \\
\hline Little loser & 0.898 & 0.371 \\
\hline
\end{tabular}

*statistically significant differences revealed according to Student's t-test 
$62.5 \%$ of boys, and in $47.5 \%$ of girls. The results of the obtained data are presented in table 2 .

Based on the obtained data, we can conclude that the ideas about the family in adolescence differ among boys and girls. The differences between boys and girls are expressed not so much in the characteristics of the parental attitude towards the future child, but in the specific style characteristics of upbringing. As shown by the study of the types of child-parental relations between boys and girls, we revealed statistically significant differences in the indicators on the "acceptancerejection" scale $(\mathrm{t}=5.088$ at $\mathrm{p}=0,000002) ;(\mathrm{t}=2.298$ at $\mathrm{p}=0.024)$ on the scale of "cooperation"; $(\mathrm{t}=2.211$ at $\mathrm{p}=$ $0.029)$ on the scale of "symbiosis". There were no statistically significant differences among boys and girls in the indices on the "authoritarian hypersocialization" scale $(\mathrm{t}=0.716$ at $\mathrm{p}=0.475)$ and $(\mathrm{t}=0.898$ at $\mathrm{p}=0.371)$ on the "little loser" scale. The conducted empirical research has revealed a rather favorable picture of parental attitudes among young people. The revealed features of parenting relationships and parenting styles to some extent reflect the current trends in parenting.

\section{CONCLUSIONS}

The study of the ideas about the family values of young people shows that the family for the younger generation remains significant in their life along with education, professional success and social status. It has been empirically proven that the severity of the structural components of the socio-psychological readiness for marriage differs in boys and girls. The results of the methodology "Role expectations and claims in marriage" (REC) made it possible to identify the hierarchy of family values of future spouses, as well as to draw a conclusion about the socio-psychological compatibility of future spouses in the family, as well as personal initiative and responsibility for fulfilling various family functions.

According to the obtained data, we revealed statistically significant differences between the expectations and claims of boys and girls regarding marriage and family attitudes according to the scales of family values: "parental", "emotionalpsychotherapeutic", "attractiveness". Boys develop psychological readiness for marriage, they evaluate their future spouse as a communication partner. Also, they associate important life values and spheres of family life with family support and social activity. The girls develop a psychological readiness to marry a certain person, they evaluate a partner with the qualities necessary for marriage. They are more focused on a close emotional relationship with their future husband.

The results of the Parental Attitude Questionnaire (PAQ) made it possible to identify the types of attitudes of future parents towards their future children. The predominant type of parent-child relationship among boys and girls was "acceptance", the second position was the "little loser" type of relationship, and the third position was the "symbiosis" type of relationship.

We can conclude that young people, highlighting the importance of community of interests, needs, views and ideas for living together, are guided by the individual style of interpersonal interaction in the future family. Thus, the hypothesis of our study was generally confirmed that the ideas about the family in adolescence differ in boys and girls.

The practical significance of the research results is determined by the fact that the revealed features of readiness for marriage in boys and girls, which were obtained in the process of empirical work, can be taken into account and used in the development of a program aimed at preparing the younger generation for the creation of a family. Moreover, these results can be used in individual and family counseling.

\section{REFERENCES}

[1] V.V. Solodnikov, Russian Sociological and Psychological Studies of the Family in the 21st Century: A Meta-Analysis, Monitoring of Public Opinion: Economic and Social Changes 6 (2018) 269-332.

DOI: https://doi.org/10.14515/monitoring.2018.6.14

[2] V.V. Solodnikov, A Longitudinal Strategy for Researching the Quality and Changes in Marriages: Domestic Tradition and Foreign Experience (Review of Theories, Methods and Research). Public Opinion Monitoring: Economic and Social $\begin{array}{llll}\text { Changes } & 1 & \text { (2016) 3-20. DOI: }\end{array}$ https://doi.org/10.14515/monitoring.2016.1.01

[3] B.R. Karney, T.N. Bradbury, Longitudinal changes in the quality and stability of marriage: a review of theories, methods and research (tr. from Eng. By R. Evdokimov, D. Pecherskiy; intr. by V.V. Solodnikov). Public Opinion Monitoring: Economic and Social Change 1 (2016) 21-99. DOI: https://doi.org/10.14515/monitoring.2016.1.02

[4] D. Umberson, K. Williams, D.A. Powers et al., As Good as it Gets? Quality of marriage in the context of the life path (Tr. from Eng. by R. Evdokimov; Intr. by V.V Solodnikov), Public Opinion Monitoring: Economic and Social Change 1 (2016) 100-125.

DOI: https://doi.org/10.14515/monitoring.2016.1.03

[5] N.N. Tolstykh, Modern growing up. Counseling psychology and psychotherapy Vol. 23 Iss. 4 (2015) 7-24. DOI: 
[6] E.N. Volkova, Psychological characteristics of the subjectivity of gifted adolescents. Herzen University Bulletin 197 (2020) 52-62. DOI: https://doi.org/10.33910/1992-6464-2020-197-5262

[7] C. Sebastian, S. Burnett, S. Blakemore, Development of the self-concept during adolescence, Trends in Cognitive Sciences 12(11) (2008) 441-446. DOI: https://doi.org/10.1016 / j.tics.2008.07.008

[8] Z.P. Zamaraeva, G.A. Telegina, Sociological portrait of the modern Russian family. PSTU Bulletin, Socio-economic sciences 4 (2017) 19. DOI: https://doi.org/10.15593/2224$\underline{9354 / 2017.4 .19}$

[9] P. Amato, The impact of family formation change on the cognitive, social, and emotional well-being of the next generation. Future Child 15(2) (2005) 7596. DOI: https://doi.org/10.1353/foc.2005.0012

[10] Thomas J., O'Connor, Dunn J., Jennifer M. Jenkins, Rasbash J.: Predictors of interfamily and intrafamily variation in parent-child relationships. Child mental psychiatry 47(5) (2006) 498-510. DOI: https://doi.org/10.1111/j.1469-7610.2005.01527.x

[11] O.S.O. Gelmez, B. Hatiboglu, C. Öngen, Pathways from personal towards professional values: Structured small-group work with social work students. Education as Change, Vol. 23, 2019. DOI: https://doi.org/10.25159/1947-9417/4418

[12] J.J. Arnett, Emerging adulthood(s): The cultural psychology of a new life stage, In J.J. Arnett (Ed), Bridging cultural and developmental approaches to psychology: New synthesis in theory, research, and policy, Oxford: University Press, 2011, pp. 255-275. DOI:

https://doi.org/10.1093/acprof:oso/9780195383430. $\underline{003.0012}$

[13] A. Koch, V.A. Orlov, Values and professional selfdetermination of student youth, Education and Science, Vol. 22, Iss. 2, 2020. DOI: https://doi.org/10.17853/1994-5639-2020-2-141$\underline{168}$

[14] A.P. Makarova, Values of Student Youth. Contemporary studies of social problems, 2018, Vol. 9, Iss. 10. DOI: https://doi.org/10.12731/22187405-2018-10-92-104

[15] D. Baumrind, Influence of parenting style on the competence of adolescents and the use of psychoactive substances, University of California at Berkeley Vol. 11 Iss. 1 (1991) 56-95. DOI: https://doi.org/10.1177/0272431691111004
[16] V.V. Retivina, Labor values and attitudes of modern student youth, Higher education in Russia Vol. 29 Iss. 1 (2019) 57-63. DOI: https://doi.org/10.31992/0869-3617-2019-28-1-57$\underline{63}$ 